\title{
Organ Fabrication Using Pigs as An in Vivo Bioreactor
}

\author{
Eiji Kobayashi, ${ }^{1}$ Shugo Tohyama ${ }^{1,2}$ and Keiichi Fukuda ${ }^{2}$ \\ ${ }^{1}$ Department of Organ Fabrication, Keio University School of Medicine, Tokyo, Japan \\ ${ }^{2}$ Department of Cardiology, Keio University School of Medicine, Tokyo, Japan
}

(Received for publication on May 23, 2019)

(Revised for publication on July 15, 2019)

(Accepted for publication on July 17, 2019)

(Published online in advance on August 6, 2019)

\begin{abstract}
We present the most recent research results on the creation of pigs that can accept human cells. Pigs in which grafted human cells can flourish are essential for studies of the production of human organs in the pig and for verification of the efficacy of cells and tissues of human origin for use in regenerative therapy. First, against the background of a worldwide shortage of donor organs, the need for future medical technology to produce human organs for transplantation is discussed. We then describe proofof-concept studies in small animals used to produce human organs. An overview of the history of studies examining the induction of immune tolerance by techniques involving fertilized animal eggs and the injection of human cells into fetuses or neonatal animals is also presented. Finally, current and future prospects for producing pigs that can accept human cells and tissues for experimental purposes are discussed. (DOI: 10.2302/kjm.2019-0006-OA; Keio J Med 69 (2) : 30-36, June 2020)
\end{abstract}

Keywords: organ fabrication, donor shortage, in vivo bioreactor, pig, stem cell

\section{Introduction}

Organ transplantation has become well established as "the wonder treatment" of the 20th century as a final treatment for patients with organ failure and no other hope for survival. ${ }^{1}$ While the prognosis for transplant patients has dramatically improved, there is a chronic worldwide shortage of donor organs. This profound shortage of organs has encouraged the unethical or illegal sourcing of donors. In an early initiative of the 2008 Istanbul Declaration, professionals engaged in organ transplantation demanded the following guarantees: (1) opposition to organ trafficking and transplant commercialism, (2) promotion of transplantation from deceased donors in the same country and/or region, and (3) protection and following up of living donors. ${ }^{2}$ Various efforts have been made in many countries, but 10 years later, the organ shortage has not improved. E.K., one of the authors, has participated in living donor liver transplantation in clinical practice in Japan. ${ }^{3}$ Living donor transplantation was developed as the sole alternative in the absence of a deceased do- nor and has saved many lives. However, there is a great demand for next-generation medical treatments to render organ transplantation unnecessary, e.g., promotion of the concept of the production of "transplantable organs" in patients themselves and research and development of specific techniques to this end. ${ }^{4}$

Much progress has been made in recent years in the fundamental research of stem cells. Techniques for the testtube production of organs from pluripotent cells can be applied to humans. Human embryonic stem cells (ESCs) ${ }^{5}$ and human induced pluripotent stem cells (iPSCs) ${ }^{6}$ have been produced as human pluripotent stem cells. These achievements are promising for research into the production of vital organs in the laboratory. One current issue is the need for reactors that provide the infrastructure for organ development and also supply oxygen and nutrition for the continued production and growth of organs. The pig has been identified as the animal most likely to provide the required in vivo reactor infrastructure. As the next step, pigs that can accept human cells and tissues must be produced. To achieve this, techniques for suppressing im- 
munity in the pig to enable acceptance of human cells and for inducing immune tolerance to cells must be evaluated. Immunosuppression has been successful in pigs ${ }^{7-11}$; however, unlike for small animals, management of the rearing of these immunocompromised pigs makes organ production scientifically and economically difficult. ${ }^{12}$

In this review, we first provide an overview of recent studies on the production of human tissues and organs in living pigs. After describing studies related to immune tolerance (which involves elimination of immune responses in individual animals), we introduce recent research on the production of pigs that can accept human cells and tissues.

\section{Proof of Concept in Small Animals of Techniques for Growing Human Organs in Pigs}

The technology used for producing antibodies or drugs to be used in humans and for producing cells and/or tissues of human origin in the bodies of living animals are referred to as "animal factories" or in vivo bioreactors. Pigs have attracted much attention in this respect: in addition to the history and social importance of the hygienic management of the pig as a food animal, in recent years it has also been evaluated for developmental engineering purposes. It is an additional advantage that they give birth to multiple offspring from the economical and ethical points of view.

In studies of transplantation between mice and rats, we successfully replaced, in vivo, the livers of mice with rat hepatocytes, which were then transplanted into rats. ${ }^{13}$ Rat hepatocytes were injected into severe combined immunodeficient (SCID) mouse pups. For use as an in vivo bioreactor, the mice were subjected to genetic procedures that caused progressive damage to the liver, preventing its development. As the SCID mice grew, the livers were replaced with rat hepatocytes. In the livers of mice produced using this technique, more than $95 \%$ of cells were replaced with rat hepatocytes. Although the vascular system and biliary system were still murine, when such livers were transplanted with blood vessels attached into the rat as a recipient, the recipient rat were extremely immunologically viable and showed long-term survival. ${ }^{13}$ However, the mice as in vivo reactors must be SCID to accept injected xenogenic rat cells. Evidently, SCID pigs would be required to verify this principle in human-sized pigs. However, the extremely high costs of reproduction and hygiene management of SCID pigs is a considerable limitation to the future development of this approach.

Nakauchi et al. have established a developmental engineering method for heterogeneic mouse-rat transplantation of the pancreas in which the target organ increased ${ }^{14)}$. In this technique, a key gene associated with organ development in the mouse is knocked out and, after fertilization, the blastocyst of knocked out mice is complemented with rat iPSCs. Mice born using this procedure contain rat pancreatic islets of Langerhans. Islets of Langerhans taken from the mouse pancreas produced an effect when transplanted into diabetes-induced rats. ${ }^{14}$ For this strategy, apancreatic pig that did not develop a pancreas have also been successfully produced, and it has been demonstrated that after blastocyst exchange with a healthy pig, a pancreas is formed from the exogenous cells as the apancreatic pig could not survive for a long time. ${ }^{15}$ This technique produces xenogenic chimera at the level of the fetus, and animals capable of development can grow with normal immunocompetence. In recent years, the production of pig-human chimera at the fetal level was also performed at the Salk Institute (USA). ${ }^{16}$ They showed that human ESCs or iPSCs could be introduced into fertilized pig eggs to produce a human-pig chimera. However, this technique raises serious ethical questions. Consequently, there are limitations to creating a chimera with a mixture of pig and human cells that are introduced at the fetal level. For human-pig chimeras, it has been said that "such a horrible creature should not be brought to term." Moreover, the introduction of heterologous cells and genes during insemination must be thoroughly considered, not only from the perspective of legal problems regarding the insemination procedure, but also for the loss of the personal identity of a living being. To better understand the production of the human-pig xenogenic chimera, we summarize these approaches for human cell injection into the pig in Fig. 1.

Overcoming the ethical issue of xeno-chimera, the methods for inducing immune tolerance by injecting human cells into pig fetuses have been reconsidered. Numerous studies have examined heterogeneic cell transplantation. Experiments inducing immune tolerance within the same species are free from the ethical and legal problems described above. This history of the concept of immune tolerance is reviewed in the next section.

\section{Historical Background of Immune Tolerance}

Medawer, who together with Burnet, won the Nobel Prize in 1960 for Physiology and Medicine, reviewed the progress of immunological tolerance at the time. ${ }^{17}$ Medawer first described the work of Owen in 1945. Owen investigated more than 80 pairs of twin calves, nearly all of which had the same blood type, ${ }^{18}$ and discovered that individual calves that experience anastomosis in the placenta accepted the exchange of skin grafts after maturity. In multiple fetuses of different sexes, female fetuses, in which there is abnormal differentiation of the reproductive organs causing infertility, are called freemartins and are the result of blood chimerism produced by placental anastomosis. The sex chromosomes show XX/XY chimerism, which is thought to exist at $1-2 \%$ in the Holstein breed.

In 1950, Hasek reported that this phenomenon could be reproduced experimentally in different species. He 

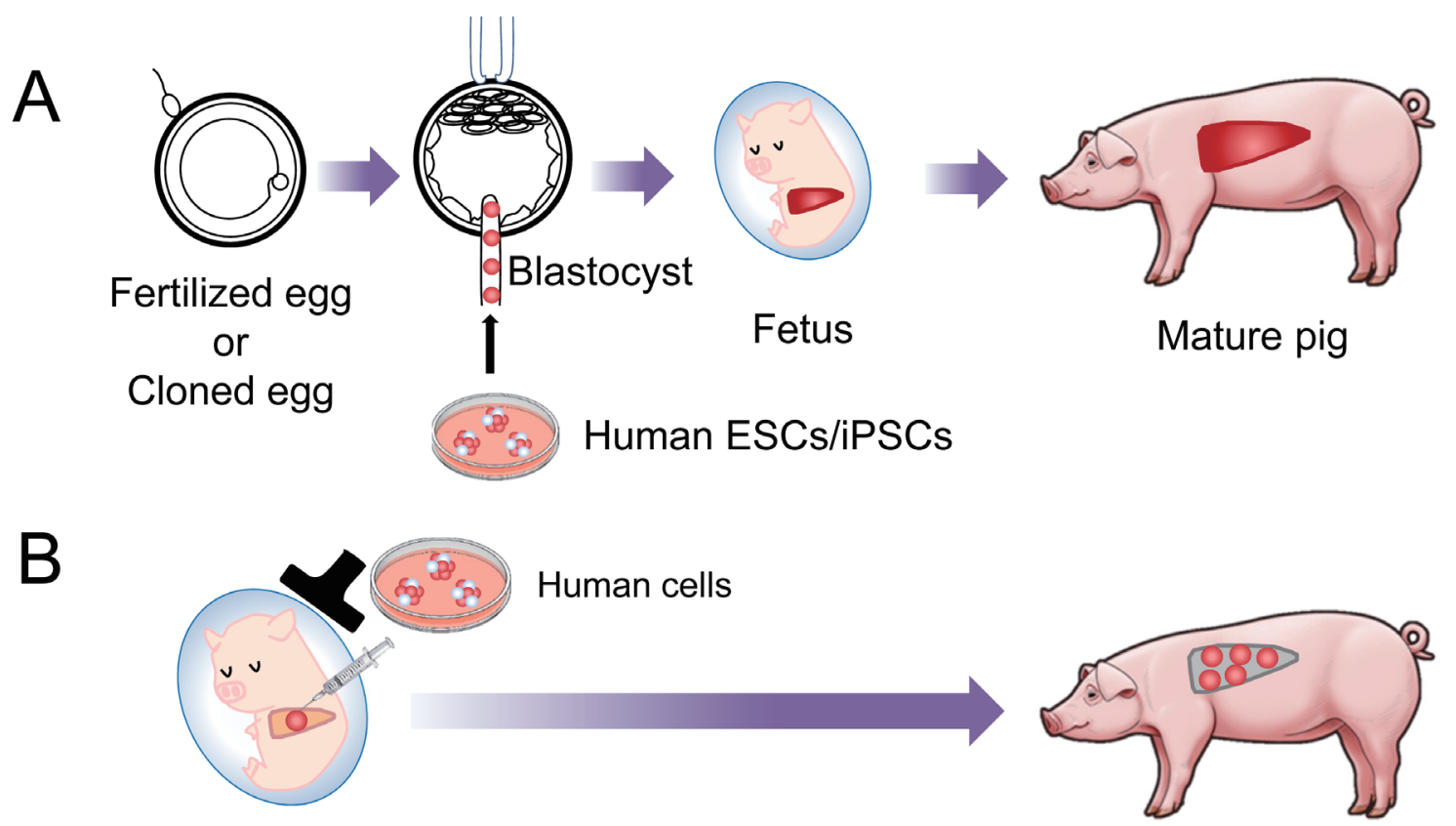

Fetus
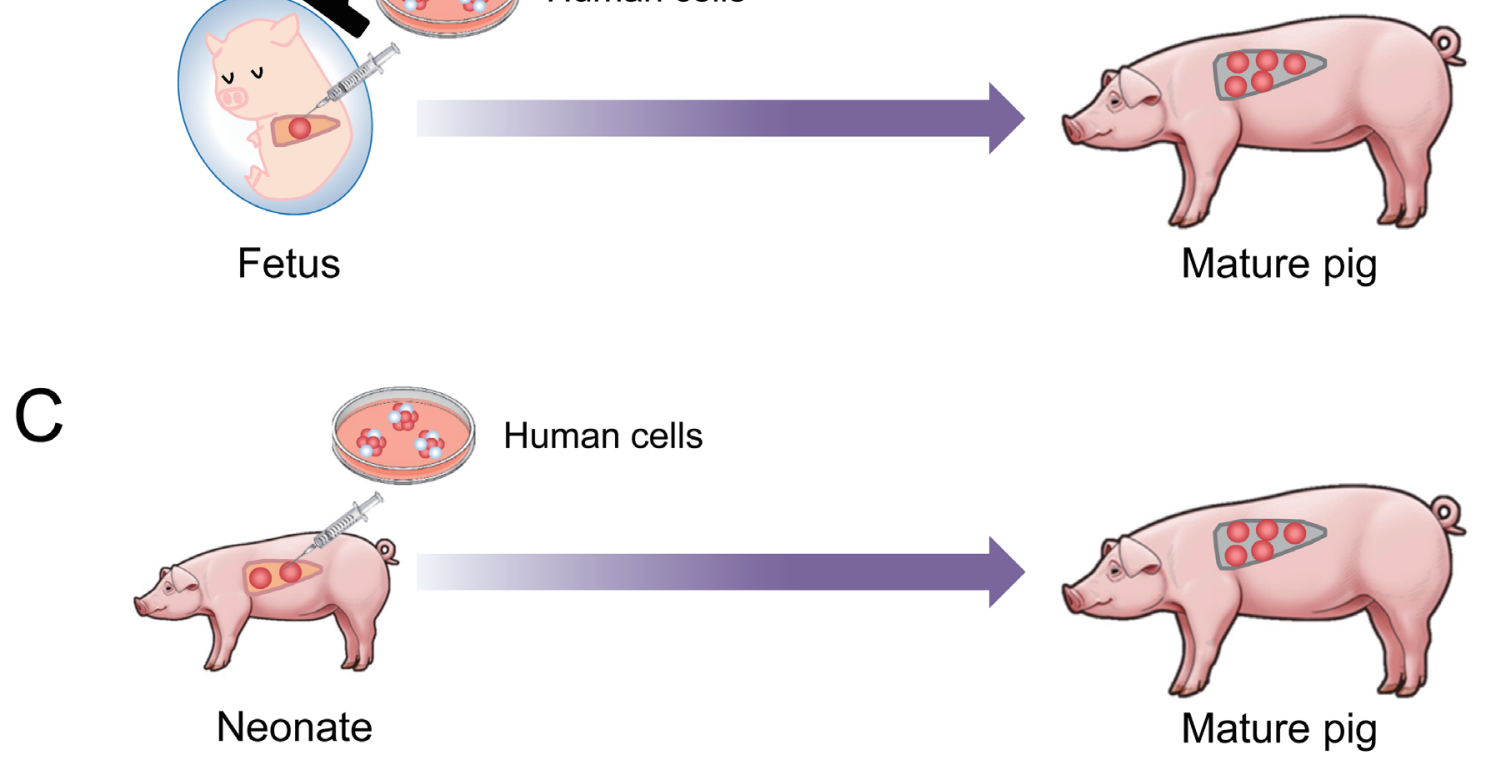

Fig. 1. Various approaches to human organ development in pigs.

(A) Pigs with human liver created by blastocyst complementation have been introduced as the embryonic approach. Human ESCs or iPSCs can be injected into pig eggs in which the master gene for liver formation has been knocked out. The developing egg is implanted to a pseudopregnant mother pig. The pig fetus has a human liver from the developmental stage because human stem cells engraft the liver site. As a result, pigs with human livers can be produced. Schematics show fetal (B) and neonatal (C) approaches via injection of human cells into fetal or neonatal pig's organ. Immune insufficient pigs with human hepatocytes gradually develop under apoptosis of pig hepatocytes by use of the conditional knockout method. Finally, chimeric human liver is obtained with a pig liver scaffold.

produced parabiosis in fertilized eggs of chicken and Pekin ducks and demonstrated that the birds, which were subsequently hatched, did not produce antibodies when immunized with the blood of the other species. ${ }^{19}$ Hasek inferred that, in addition to the blood chimerism discovered by Owen, this phenomenon was induced at this point of the life cycle. In 1953, Medawar et al. conducted experiments in which immune tolerance was established in the fetuses of mice or embryonic chicks by implanting a live antigen. ${ }^{20}$ They termed this phenomenon "actively acquired tolerance."

In 1969, at Cambridge University, UK, Calne reported examples of liver transplantation between pigs with different graft antigens in which tolerance was acquired without the use of immunosuppressants. ${ }^{21}$ At the same time, Calne enabled liver transplantation through the clinical application of immunosuppressants. This phenomenon, named liver tolerance, was advanced by the same group using rats with a clearly defined genetic background. ${ }^{22}$ Around the same time, Binns, also in Cambridge, evaluated the actively acquired tolerance demonstrated by Medawer in small animals, such as mice, and induced immune tolerance in pig fetuses by implanting them with bone marrow cells or lymphocytes from another pig. ${ }^{23}$ 
He reported that it is difficult to induce immune tolerance unless it is within 60 gestational days. Moreover, the same group attempted to induce an immunosuppressed state by removing the thymus during the neonatal period. In pigs on the contrary, unlike in mice, $\mathrm{T}$ cells start to appear during the neonatal period, but it is known that an immunosuppressed state can be induced to a certain extent. $^{24}$

Mice and pigs differ greatly in body size, leading to large differences in the costs of experimentation. However, previous studies provided a great deal of knowledge on the concept of using pigs as bioreactors and preclinical experimental systems. ${ }^{21,25}$

\section{Current and Future Prospects for Production of Pigs That Can Accept Human Cells}

Pigs are very similar to humans in body size and in the structure and metabolism of the internal organs. Consequently, pigs are extremely important as a preclinical model for verifying the safety and efficacy of products and techniques for regenerative medicine. However, the progress in verifying differentiation induction in human pluripotent cells in recent years has led to the need for transplantation of the resulting cells in immunocompromised animals and pathological verification of tridermic differentiation. ${ }^{26}$ Currently, multiple immunosuppressants administered in clinical practice to humans (e.g., tacrolimus, mycophenolate mofetil, and steroids) must be used to achieve survival of cells of human origin in pigs. ${ }^{27}$ However, the immune response is stronger than the human-monkey response, ${ }^{28}$ and thus severe drug regimens and management of these drugs are necessary.

At Keio University School of Medicine, clinical applications of regenerative therapy using human iPSCderived cardiomyocytes and neural precursor cells are underway, mainly in the Department of Cardiology and the Department of Orthopedic Surgery, respectively. In this section, we discuss the findings from research on the production of pigs that can accept human cells and tissues, evaluated in the Department of Organ Fabrication at Keio University School of Medicine.

Immunosuppression by total thymectomy in neonatal pigs was first reported in 1972 by Binns et al. The world's smallest experimental miniature pig, the micro-mini pig (MMP), was developed in Japan. ${ }^{29-31}$ Since 2012, total thymectomy has been carried out in MMP piglets delivered by caesarian section in a specific pathogen-free environment, with observation over at least 2 years (Fig. 2). MMPs were selected because, even when mature, the animals are smaller than domestic pigs or even ordinary miniature pigs, thereby facilitating long-term monitoring of the safety and efficacy of cells and tissues for regenerative medicine. There was no difference in the body weight during growth between athymic and control MMPs under specific pathogen-free conditions. However, the thy- mic hormone thymosin- $\alpha 1$ was maintained at a low level in the athymic MMPs throughout the observation period. In addition, although no significant decrease was noted during flow cytometric verification of T-cell numbers among peripheral lymphocytes, there was a decrease in the in vitro proliferation of peripheral lymphocytes in response to pokeweed mitogen. In this model, human hepatocytes were grafted into the athymic MMP liver without using an immunosuppressant, and the effect was verified by measuring peripherally expressed albumin. Whereas, in the control group, human albumin decreased to below the limit of detection within 1 week, human albumin was detected in the peripheral blood of the tested MMPs for 2-3 weeks ${ }^{32}$. These athymic MMPs are now available commercially, and various laboratories have begun to use them.

We have also carried out surgical improvement in ordinary mature miniature pigs to facilitate grafting of human cells and tissues. In this method, the thymus and spleen of mature miniature pigs are surgically removed and the pigs are fed immunosuppressants through a stomach tube ${ }^{33}$ (Fig. 3). Artificial blood vessels produced by 3D printing of clumps of human fibroblast cells were surgically inserted and monitored as shunts into the carotid artery and jugular vein of these pigs. Following prior administration of three immunosuppressants, shunt flow in the inserted vessels ceased within 1 month in all animals with intact thymus and spleen (control group), but for the system described above, favorable blood flow was maintained for several months in operatively immunodeficient pigs. We refer to these pigs as operational SCID pigs, because they are produced by using surgical procedures and immunosuppressant administration. ${ }^{33}$

Methods for inducing immune tolerance by injecting a human antigen into pig fetuses or neonatal piglets are also being developed. The initial point of reference for the method of injecting human cells into the thymus is a historic experiment in small animals carried out by Posselt et al. in 1990. After causing the collapse of the immune system by extreme administration of antilymphocyte serum, target donor islets were injected into the thymus (because the thymus has an immunoisolating capacity) and immune tolerance was induced. ${ }^{34}$ After removing piglets from a gestating MMP under general anesthesia, we injected human iPSCs or iPSC-derived cardiomyocytes into the thymus of the piglets. After rearing these piglets for 1 month, the challenge was repeated by grafting similar cells subcutaneously under the renal capsule and into the thymus. However, the transplanted human cells were clearly subject to immunorejection.

Actively acquired tolerance has been induced between different species, including between humans and sheep. ${ }^{35}$ In this study, human mesenchymal stem cells were implanted into a sheep fetus, and the lamb was reared to maturity and then shown to be a human-sheep chimera. Fujiki et al. administered human cord blood to fetal 

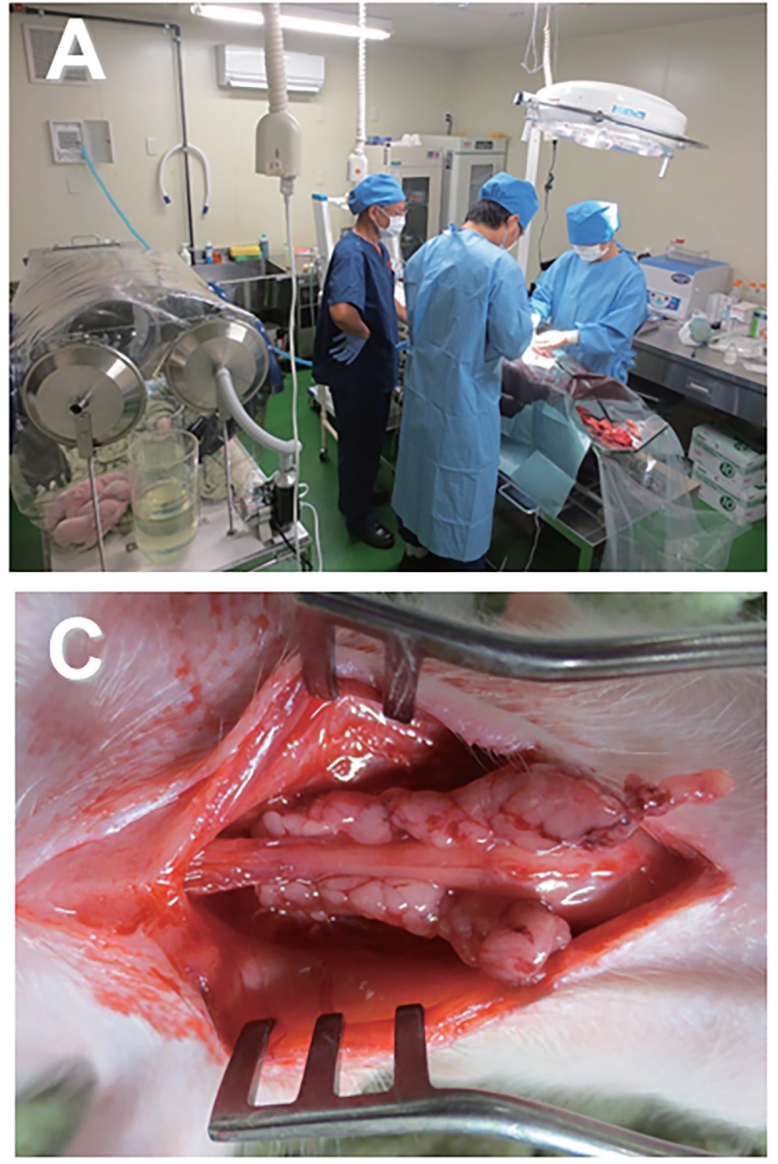
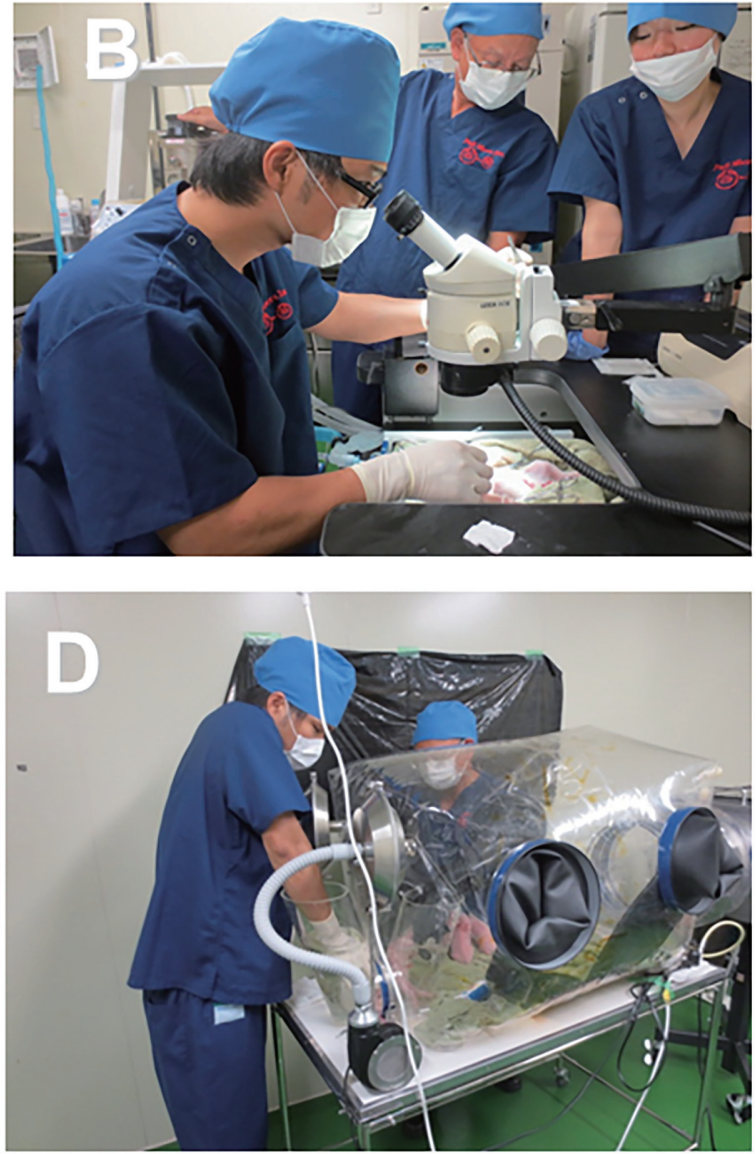

Fig. 2 Total thymectomy in the neonatal pig.

(A) Caesarean section in micro-mini pigs. (B) Total thymectomy under microscopic guidance. (C) Total view of the neonatal thymus.

(D) The treated neonates were kept under specific-pathogen-free conditions.

pigs. ${ }^{36}$ In all of these studies, pathological verification after growth of the fetus and genetic analysis by PCR, among other techniques, demonstrated that cells from the donor were in a chimeric state. These attempts to induce actively acquired tolerance have further attracted attention for their potential in postnatal acceptance of human cells. ${ }^{37}$ Therefore, we plan to transplant human cells into fetal MMPs to induce actively acquired tolerance.

\section{Concluding Remarks}

Research on the production of human organs in the bodies of pigs has accelerated because of recent progress in human stem cell research and developmental engineering techniques. In pigs subjected to these techniques, immune tolerance to cells of human origin or a non-immunoreactive state has been induced, and such pigs may be useful as a preclinical system for verifying the safety and effect of cells intended for human regenerative medicine. Safety of human cells/tissue developed in pigs will need to be tested from the viewpoint of infectious disease and the risk of malignancy, among others, before transplantation in patients can be considered.

\section{Acknowledgments}

In this study, research on the adsorption and proliferation of human cells in the spleens of pigs was conducted with Dr. Shin Enosawa at the National Center for Child Health and Development as a collaborative research with Sysmex Corporation. Human artificial vascular tubes inserted in operational SCID pigs by the administration of immunosuppresive agents were carried out with Professor Koichi Nakayama and Dr. Manabu Itoh of Saga University. Research on the induction of immune tolerance by injecting human-derived iPS cells into neonatal miniature pigs was conducted with Professors Takashi Mori and Masaki Takasu of Gifu University as a collaborative research project. The researchers were supported by grants from Sysmex Corporation. The work was carried out at the Keio University School of Medicine, Department of Organ Fabrication. All experimental procedures 

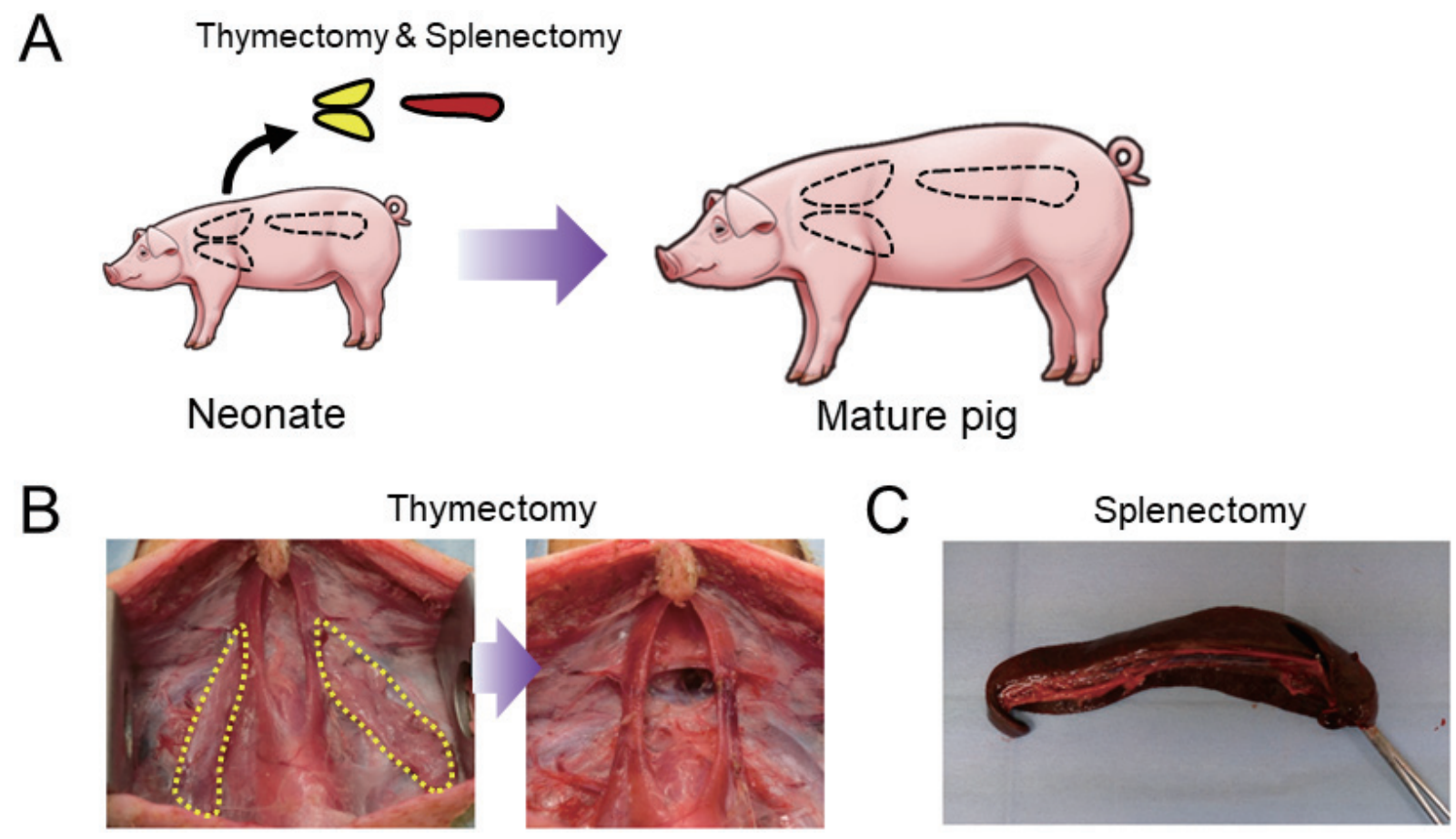

Fig. 3 Development of operational SCID Pigs.

(A) Schematic showing the procedure for developing an operational SCID Pig. (B) Photograph of thymectomy in a mature mini-pig model. (C) Photograph of the resected spleen in a mature mini-pig model. Adapted from Itoh et al., Nature Communications, 2019 (DOI:10.1038/s41467-019-10107-1), Fig. 1. (Copyright 2019 Itoh et al. Used under the Attribution 4.0 International CC BY 4.0 License: https://creativecommons.org/licenses/by/4.0/).

were approved by the Ethics Committee of Keio University School of Medicine.

\section{Conflicts of Interest}

E.K. is a medical advisor of Sysmex Corporation. This study was supported by grants from Sysmex Corporation.

\section{References}

1. Morris PJ: Transplantation - a medical miracle of the 20th century. N Engl J Med 2004; 351: 2678-2680. PMID:15616201, DOI:10.1056/NEJMp048256

2. Steering Committee of the Istanbul Summit: Organ trafficking and transplant tourism and commercialism: The Declaration of Istanbul. Lancet 2008; 372: 5-6. PMID:18603141, DOI:10.1016/ S0140-6736(08)60967-8

3. Mizuta K, Sanada Y, Wakiya T, Urahashi T, Umehara M, Egami S, Hishikawa S, Okada N, Kawano Y, Saito T, Hayashida M, Takahashi S, Yoshino H, Shimizu A, Takatsuka Y, Kitamura T, Kita Y, Uno T, Yoshida Y, Hyodo M, Sakuma Y, Fujiwara T, Ushijima K, Sugimoto K, Ohmori M, Ohtomo S, Sakamoto K, Nakata M, Yano T, Yamamoto H, Kobayashi E, Yasuda Y, Kawarasaki $\mathrm{H}$ : Living-donor liver transplantation in 126 patients with biliary atresia: single-center experience. Transplant Proc 2010; 42: 41274131. PMID:21168643, DOI:10.1016/j.transproceed.2010.11.002

4. Kobayashi E: Challenges for production of human transplantable organ grafts. Cell Med 2017; 9: 9-14. PMID:28174670, DOI:10.3727/215517916X693113
5. Thomson JA, Itskovitz-Eldor J, Shapiro SS, Waknitz MA, Swiergiel JJ, Marshall VS, Jones JM: Embryonic stem cell lines derived from human blastocysts. Science 1998; 282: 1145-1147. PMID:9804556, DOI:10.1126/science.282.5391.1145

6. Takahashi K, Tanabe K, Ohnuki M, Narita M, Ichisaka T, Tomoda $\mathrm{K}$, Yamanaka S: Induction of pluripotent stem cells from adult human fibroblasts by defined factors. Cell 2007; 131: 861-872. PMID:18035408, DOI:10.1016/j.cell.2007.11.019

7. Ito T, Sendai Y, Yamazaki S, Seki-Soma M, Hirose K, Watanabe M, Fukawa K, Nakauchi H: Generation of recombination activating gene-1-deficient neonatal piglets: a model of T and B cell deficient severe combined immune deficiency. PLoS One 2014; 9: e113833. PMID:25437445, DOI:10.1371/journal.pone.0113833

8. Huang J, Guo X, Fan N, Song J, Zhao B, Ouyang Z, Liu Z, Zhao Y, Yan Q, Yi X, Schambach A, Frampton J, Esteban MA, Yang D, Yang H, Lai L: RAG1/2 knockout pigs with severe combined immunodeficiency. J Immunol 2014; 193: 1496-1503. PMID:24973446, DOI:10.4049/jimmunol.1400915

9. Lee K, Kwon DN, Ezashi T, Choi YJ, Park C, Ericsson AC, Brown AN, Samuel MS, Park KW, Walters EM, Kim DY, Kim JH, Franklin CL, Murphy CN, Roberts RM, Prather RS, Kim JH: Engraftment of human iPS cells and allogeneic porcine cells into pigs with inactivated RAG2 and accompanying severe combined immunodeficiency. Proc Natl Acad Sci USA 2014; 111: 7260-7265. PMID:24799706, DOI:10.1073/pnas.1406376111 
10. Watanabe M, Nakano K, Matsunari H, Matsuda T, Maehara M, Kanai T, Kobayashi M, Matsumura Y, Sakai R, Kuramoto M, Hayashida G, Asano Y, Takayanagi S, Arai Y, Umeyama K, Nagaya M, Hanazono Y, Nagashima H: Generation of interleukin-2 receptor gamma gene knockout pigs from somatic cells genetically modified by zinc finger nuclease-encoding mRNA. PLoS One 2013; 8: e76478. PMID:24130776, DOI:10.1371/journal. pone. 0076478

11. Suzuki S, Iwamoto M, Saito Y, Fuchimoto D, Sembon S, Suzuki M, Mikawa S, Hashimoto M, Aoki Y, Najima Y, Takagi S, Suzuki N, Suzuki E, Kubo M, Mimuro J, Kashiwakura Y, Madoiwa S, Sakata Y, Perry AC, Ishikawa F, Onishi A: Il2rg gene-targeted severe combined immunodeficiency pigs. Cell Stem Cell 2012; 10: 753-758. PMID:22704516, DOI:10.1016/j.stem.2012.04.021

12. Matsunari H, Watanabe M, Nakano K, Enosawa S, Umeyama K, Uchikura A, Yashima S, Fukuda T, Klymiuk N, Kurome M, Kessler B, Wuensch A, Zakhartchenko V, Wolf E, Hanazono Y, Nagaya M, Umezawa A, Nakauchi H, Nagashima H: Modeling lethal $\mathrm{X}$-linked genetic disorders in pigs with ensured fertility. Proc Natl Acad Sci USA 2018; 115: 708-713. PMID:29311328, DOI:10.1073/ pnas. 1715940115

13. Hata T, Uemoto S, Fujimoto Y, Murakami T, Tateno C, Yoshizato K, Kobayashi E: Transplantation of engineered chimeric liver with autologous hepatocytes and xenobiotic scaffold. Ann Surg 2013; 257: 542-547. PMID:22691372, DOI:10.1097/ SLA.0b013e31825c5349

14. Yamaguchi T, Sato H, Kato-Itoh M, Goto T, Hara H, Sanbo M, Mizuno N, Kobayashi T, Yanagida A, Umino A, Ota Y, Hamanaka S, Masaki H, Rashid ST, Hirabayashi M, Nakauchi H: Interspecies organogenesis generates autologous functional islets. Nature 2017; 542: 191-196. PMID:28117444, DOI:10.1038/nature21070

15. Matsunari H, Nagashima H, Watanabe M, Umeyama K, Nakano K, Nagaya M, Kobayashi T, Yamaguchi T, Sumazaki R, Herzenberg LA, Nakauchi H: Blastocyst complementation generates exogenic pancreas in vivo in apancreatic cloned pigs. Proc Natl Acad Sci USA 2013; 110: 4557-4562. PMID:23431169, DOI:10.1073/ pnas. 1222902110

16. Wu J, Platero-Luengo A, Sakurai M, Sugawara A, Gil MA, Yamauchi T, Suzuki K, Bogliotti YS, Cuello C, Morales Valencia M, Okumura D, Luo J, Vilariño M, Parrilla I, Soto DA, Martinez CA, Hishida T, Sánchez-Bautista S, Martinez-Martinez ML, Wang H, Nohalez A, Aizawa E, Martinez-Redondo P, Ocampo A, Reddy P, Roca J, Maga EA, Esteban CR, Berggren WT, Nuñez Delicado E, Lajara J, Guillen I, Guillen P, Campistol JM, Martinez EA, Ross PJ, Izpisua Belmonte JC: Interspecies chimerism with mammalian pluripotent stem cells. Cell 2017; 168: 473-486.e15. PMID:28129541, DOI:10.1016/j.cell.2016.12.036

17. Medawar PB: Immunological tolerance. Nature 1961; 189: 14-17. PMID:13768821, DOI:10.1038/189014a0

18. Owen RD: Immunogenetic consequences of vascular anastomoses between bovine twins. Science 1945; 102: 400-401. PMID:17755278, DOI:10.1126/science.102.2651.400

19. Hašek M, Hraba T: Immunological effects of experimental embryonal parabiosis. Nature 1955; 175: 764-765. PMID:14370214, DOI:10.1038/175764a0

20. Billingham RE, Brent L, Medawar PB: Actively acquired tolerance of foreign cells. Nature 1953; 172: 603-606. PMID:13099277, DOI:10.1038/172603a0

21. Calne RY, Sells RA, Pena JR, Davis DR, Millard PR, Herbertson BM, Binns RM, Davies DA: Induction of immunological tolerance by porcine liver allografts. Nature 1969; 223: 472-476. PMID:4894426, DOI:10.1038/223472a0

22. Kamada N, Davies HS, Roser B: Reversal of transplantation immunity by liver grafting. Nature 1981; 292: 840-842. PMID:7022223, DOI:10.1038/292840a0
23. Binns RM: Bone marrow and lymphoid cell injection of the pig foetus resulting in transplantation tolerance or immunity, and immunoglobulin production. Nature 1967; 214: 179-181. PMID:4166491, DOI:10.1038/214179a0

24. Binns RM, McFarlin DE, Sugar JR: Lymphoid depletion and immunosuppression after thymectomy in the young pig. Nat New Biol 1972; 238: 181-183. PMID:4559281, DOI:10.1038/newbio238181a0

25. Calne RY, Bitter-Suermann H, Davis DR, Dunn DC, Herbertson BM, Reiter FH, Sampson D, Smith DP, Webster LM: Orthotopic heart transplantation in the pig. Nature 1974; 247: 140-142. PMID:4589451, DOI:10.1038/247140b0

26. Masuda S, Yokoo T, Sugimoto N, Doi M, Fujishiro SH, Takeuchi K, Kobayashi E, Hanazono Y: A simplified in vitro teratoma assay for pluripotent stem cells injected into rodent fetal organs. Cell Med 2012; 3: 103-112. PMID:28058187, DOI:10.3727/215517912X639351

27. Kawamura M, Miyagawa S, Fukushima S, Saito A, Toda K, Daimon T, Shimizu T, Okano T, Sawa Y: Xenotransplantation of bone marrow-derived human mesenchymal stem cell sheets attenuates left ventricular remodeling in a porcine ischemic cardiomyopathy model. Tissue Eng Part A 2015; 21: 2272-2280. PMID:26046810, DOI:10.1089/ten.tea.2014.0036

28. Sakai R, Kitano E, Maeda A, Lo P, Eguchi H, Watanabe M, Nagashima H, Okuyama H, Miyagawa S: Studies of innate immune systems against human cells. Transpl Immunol 2017; 40: 66-71. PMID:27939210, DOI:10.1016/j.trim.2016.12.002

29. Kobayashi E, Hishikawa S, Teratani T, Lefor AT: The pig as a model for translational research: overview of porcine animal models at Jichi Medical University. Transplant Res 2012; 1: 8. PMID:23369409, DOI:10.1186/2047-1440-1-8

30. Kobayashi E, Hanazono Y, Kunita S: Swine used in the medical university: overview of 20 years of experience. Exp Anim 2018; 67: 7-13. PMID:28993564, DOI:10.1538/expanim.17-0086

31. Tohyama S, Kobayashi E: Age-appropriateness of porcine models used for cell transplantation. Cell Transplant 2019; 28: 224-228. PMID:30525991, DOI:10.1177/0963689718817477

32. Hsu HC, Enosawa S, Yamazaki T, Tohyama S, Fujita J, Fukuda K, Kobayashi E: Enhancing survival of human hepatocytes by neonatal thymectomy and partial hepatectomy in micro-miniature pigs. Transplant Proc 2017; 49: 153-158. PMID:28104124, DOI:10.1016/j.transproceed.2016.11.023

33. Itoh M, Mukae Y, Kitsuka T, Arai K, Nakamura A, Uchihashi K, Toda S, Matsubayashi K, Oyama J, Node K, Kami D, Gojo S, Morita S, Nishida T, Nakayama K, Kobayashi E: Development of an immunodeficient pig model allowing long-term accommodation of artificial human vascular tubes. Nat Commun 2019; 10: 2244. PMID:31113942, DOI:10.1038/s41467-019-10107-1

34. Posselt A, Barker C, Tomaszewski J, Markmann J, Choti M, Naji A: Induction of donor-specific unresponsiveness by intrathymic islet transplantation. Science 1990; 249: 1293-1295. PMID:2119056, DOI:10.1126/science. 2119056

35. Liechty KW, MacKenzie TC, Shaaban AF, Radu A, Moseley AB, Deans R, Marshak DR, Flake AW: Human mesenchymal stem cells engraft and demonstrate site-specific differentiation after in utero transplantation in sheep. Nat Med 2000; 6: 1282-1286. PMID:11062543, DOI:10.1038/81395

36. Fujiki Y, Fukawa K, Kameyama K, Kudo O, Onodera M, Nakamura Y, Yagami K, Shiina Y, Hamada H, Shibuya A, Nakauchi H: Successful multilineage engraftment of human cord blood cells in pigs after in utero transplantation. Transplantation 2003; 75: 916922. PMID:12698074, DOI:10.1097/01.TP.0000057243.12110.7C

37. Fisher JE, Lillegard JB, Mckenzie TJ, Rodysill BR, Wettstein PJ, Nyberg SL: In utero transplanted human hepatocytes allow postnatal engraftment of human hepatocytes in pigs. Liver Transpl 2013; 19: 328-335. PMID:23280879, DOI:10.1002/1t.23598 